\title{
Metode Six Sigma Dalam Perbaikan Cacat Botol pada Produk Personal Care
}

\section{Six Sigma Method in Repairing Bottle Defects in Personal Care Products}

\author{
Zulkarnain*, Tri Wicakseno, Deli Silvia \\ Program Studi Teknologi Industri Cetak Kemasan, Politeknik Negeri Jakarta \\ Jl. Prof. Dr. G. A. Siwabessy, Kampus Baru UI Depok 16424 \\ Email : triwicakseno@gmail.com,
}

\begin{abstract}
ABSTRAK
Metode six sigma digunakan untuk mendukung kualitas produk yang dihasilkan oleh suatu perusahaan. Penelitian ini dilakukan di perusahaan yang berfokus pada pembuatan botol plastik. data historis reject produksi menunjukan adanya permasalahan pada hasil produksi botol untuk produk personal care yang telah melewati batas toleransi dari target sebesar $2 \%$. fokus penelitian ini adalah pengurangan defect botol tipe personal care $500 \mathrm{ml}$. Keseluruhan defect digunakan sebagai penentu dari Critical To Quality (CTQ). Penelitian dilakukan dengan mengidentifikasi reject produk, jenis reject produksi, perhitungan nilai six sigma dan pemberian usulan perbaikan. hasil penelitian ini dengan menggunakan metode DMAIC menunjukkan angka sebesar 4.40429377 dengan DPMO sebesar 1840.413. Perbaikan dilakukan dengan menganalisis penyebab permasalahan menggunakan diagram sebab akibat. hasil analisis diagram sebab akibat adalah adanya pemberian usulan perbaikan dilakukan terhadap defect CTQ menggunakan $5 \mathrm{~W}+1 \mathrm{H}$.
\end{abstract}

Kata Kunci: Botol Plastik, DMAIC, SIPOC, Six Sigma

\begin{abstract}
The six-sigma method is used to support the quality of products produced by a company. This research was conducted in a company that focuses on making plastic bottles. Historical data on reject production shows that there are problems in the production of bottles for personal care products that have exceeded the tolerance limit of the target of $2 \%$. The focus of this research is the reduction of the $500 \mathrm{ml}$ personal care bottle defect. The entire defect is used as a determinant of Critical To Quality (CTQ). The research was carried out by identifying the reject products, the type of reject production, calculating the six-sigma value and providing improvement suggestions. The results of this study using the DMAIC method show a figure of 4.40429377 with a DPMO of 1840.413. Improvement is done by analyzing the causes of the problem using a cause-and-effect diagram. The result of the analysis of the cause-and-effect diagram is that there is a suggestion of improvement to the CTQ defect using $5 \mathrm{~W}+1 \mathrm{H}$.
\end{abstract}

Keywords: plastic bottles, DMAIC, SIPOC, Six Sigma

\section{Pendahuluan}

Persaingan ekonomi membuat beberapa perusahaan mempunyai cara tersendiri untuk memiliki arti kualitas di masyarakat. Salah satu faktor yang menjadi permasalahan untuk persaingan ini adalah reject produksi. PT X merupakan perusahaan yang bekerja pada proses blow molding dengan teknik pencetakan berupa Extrusion Blow Molding dan Injection Stretch blow Molding (ISBM). PT X memproduksi barang berupa botol yang digunakan dalam berbagai fungsi, seperti personal care, farmasi, kebutuhan rumah tangga, dan kebutuhan pendukung pekerjaan. Masalah terkait pengontrolan proses running produksi pada barang reject juga terjadi pada PT X.
Penggunaan six sigma bertujuan untuk memperbaiki sistem manajemen terkait dengan pelanggan. Perbaikan tersebut difokuskan pada pengurangan variasi proses untuk mengurangi cacat hingga mencapai 3,4 cacat per sejuta kesempatan. Penelitian mengambil studi kasus penelitian pada departemen injection di PT KG dan berfokus pada dua produk yaitu part bening Big Container 211 PLY dan Big Container 1L AS (Salomon et al., 2015). Tahap control pada penelitian six sigma dilakukan pendokumentasian dan penyebarluasan terhadap tindakan yang harus dilakukan (Didiharyono et al., 2018).

PT X memiliki prinsip continuous improvement sebagai langkah untuk meningkatkan kualitas produksi yang lebih baik. Akan tetapi, 
pengalaman di lapangan menunjukkan belum sepenuhnya penerapan metode six sigma dilakukan. Konsep six sigma memungkinkan jumlah defect yang dihasilkan untuk memiliki kategori pengendalian kualitas yang baik sebesar 3,4 unit dalam satu juta unit yang diproduksi. Rata-rata industri di Indonesia memiliki nilai sigma pada level 2 dan 3 yang terdapat pada Tabel 1 (Indrawansyah \& Cahyana, 2019). Penggunaan six sigma pada PT X diharapkan dapat mengurangi jumlah defect produk sehingga mampu bersaing dengan perusahaan lainnya hingga kelas dunia. Pada penelitian kali ini, fokus yang akan dilakukan yaitu membuat output berupa usulan perbaikan reject produksi botol tipe personal care pada proses running mesin ISBM di PT X. Usulan perbaikan ini dikhususkan kepada bagian produksi dalam mengendalikan kualitas produktivitas. Adapun tujuan yang ingin dicapai dari penelitian ini adalah :

1. Mengetahui reject yang berpengaruh pada proses ISBM beserta jenis - jenis defect.

2. Melakukan perhitungan reject produk personal care dan perhitungan nilai sigma di PT X

3. Mengusulkan perbaikan defect produk

Tabel 1. Pencapaian Nilai Sigma

Sumber: Indrawansyah dan Cahyana (2018)

\begin{tabular}{|c|c|c|c|}
\hline Persentase & Sigma & DPMO & Keterangan \\
\hline $31 \%$ & 691.462 & 1-Sigma & $\begin{array}{c}\text { Sangat tidak } \\
\text { kompetitif }\end{array}$ \\
\hline $69,20 \%$ & 308.538 & 2-Sigma & \multirow{2}{*}{$\begin{array}{l}\text { Rata-rata } \\
\text { industri } \\
\text { Indonesia }\end{array}$} \\
\hline $93,32 \%$ & 66.807 & $3-S$ & \\
\hline $99,379 \%$ & 6.210 & 4-Sigma & \multirow{2}{*}{$\begin{array}{c}\text { Rata-rata } \\
\text { industri } \\
\text { USA }\end{array}$} \\
\hline $99,977 \%$ & 233 & 5-Sigma & \\
\hline $99,9997 \%$ & 3,4 & 6-Sigma & $\begin{array}{c}\text { Industri } \\
\text { kelas dunia }\end{array}$ \\
\hline
\end{tabular}

\section{Metode Penelitian}

Metode yang dilakukan pada penelitian ini adalah metode DMAIC dari six sigma. Penggunaan six sigma dilakukan oleh suatu perusahaan salah satunya sebagai pengukuran terhadap produktivitas dan pengendalian kualitas demi mencapai standar yang ditentukan. Kondisi sigma yang baik memiliki nilai total reject sebesar 3,4 produk per sejuta kesempatan. Pencapaian ini dilakukan dengan pemberian usulan terhadap penyebab permasalahan yang mengganggu tingkat kualitas dari proses produksi beserta pengawasan terhadap pemberian usulan.

Penelitian ini dilakukan dengan menganalisis masalah reject produk botol personal care dengan volume $250 \mathrm{ml}$ dan $500 \mathrm{ml}$ di PT X pada proses running ISBM. Reject yang dihasilkan oleh mesin ISBM di PT X memiliki standar sebesar $2 \%$. Selain standar yang berlaku di PT X, customer memiliki standar dalam menentukan produk yang bisa disebut sebagai voice of customer.

Produk reject memiliki defect yang bervariasi. PT X melalui voice of customer membagi jenis defect menjadi 3 kategori, yaitu critical defect, major defect, dan minor defect. PT X mempunyai permasalahan defect yang harus dikurangi agar memiliki penilaian produktivitas yang baik. Usulan mengenai meminimalisasi jumlah defect pada produk perlu dilakukan sebagai langkah continuous improvement.

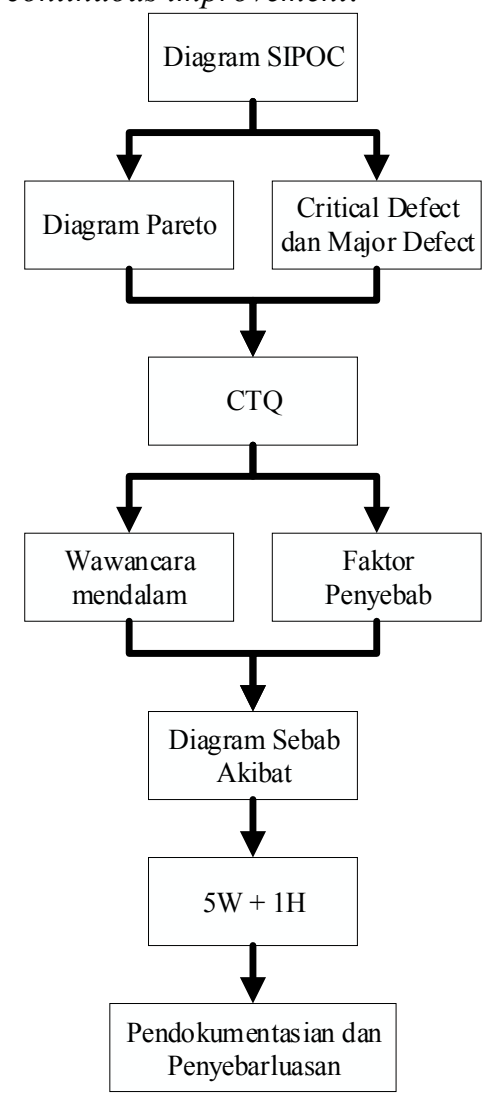

Gambar 1. Kerangka Berpikir

\section{Metode Pengumpulan Data}

Data yang diperlukan dalam penelitian ini merupakan data primer berdasarkan wawancara mengenai pengendalian kualitas dan data sekunder yang bersumber pada data running proses mesin ISBM pada periode Januari 2019 - Januari 2020 dan dokumen mesin ISBM. Jenis data tersebut bersifat kuantitatif yang meliputi jumlah produksi, dan jenis defect beserta jumlahnya pada mesin ISBM. Sedangkan data kualitatif diperoleh dengan mencari informasi tentang defect yang dihasilkan dan penyebabnya. Populasi dalam penelitian ini adalah jumlah produksi sedangkan sampel pada penelitian ini adalah jumlah cacat produk. 
Teknik pengumpulan data dilakukan dengan berbagai cara yaitu :

1. Studi literatur yang mencakup teori berdasarkan dari jurnal dan buku mengenai metode six sigma dengan proses teknik cetak blow molding.

2. Brainstorming dan wawancara kepada General Manager dan Departemen Head Produksi ISBM.

\section{Metode Analisis Data}

Analisis data dilakukan setelah melakukan tahap pengumpulan data yang diperlukan pada data produksi Personal Care Januari 2019 - Januari 2020. Pengolahan data dilakukan dengan bantuan software Microsoft Excel 2016 dan Minitab 16. Hasil dari pengolahan data selanjutnya akan dilakukan pemberian usulan perbaikan kepada perusahaan sebagai langkah perbaikan dari permasalahan reject. Pada penelitian kali ini analisis data akan diolah menggunakan langkah DMAIC. Adapun langkah yang dilakukan adalah sebagai berikut :

1. Define : Pada tahap ini dilakukan pencarian permasalahan melalui alur bisnis yang dilakukan PT X menggunakan diagram SIPOC beserta hasil. Penggunaan diagram SIPOC pada tahap define bertujuan memberikan gambaran keterlibatan alur bisnis proses dari supplier hingga customer (Kurniawan et al., 2017).

2. Measure : Pada tahap ini dilakukan pengukuran persentase cacat dengan diagram pareto dan pengukuran nilai sigma. Diagram pareto pada tahap measure menjadi penentu cacat dominan yang akan dijadikan CTQ (Ahmad, 2019). Konsep six sigma yang ingin diterapkan di perusahaan manufaktur mempunyai beberapa aspek. Salah satu aspek adalah penentu CTQ pada produk yang akan dilakukan perbaikan. CTQ dikategorikan meliputi seluruh karakteristik kualitas sesuai dengan kebutuhan dan ekspektasi pelanggan (Gaspersz, 2005). Ketidaksesuaian dibagi menjadi 3 yaitu (Kaban, 2014):

a. Kritis yaitu ketidaksesuaian yang membahayakan konsumen dan produk tidak berfungsi

b. Mayor yaitu ketidaksesuaian pada berkurangnya kinerja produk

c. Minor yaitu keetidaksesuaian pada berukurangnya kinerja produk tapi hanya mempengaruhi penampilan produk

Pada penelitian ini, keseluruhan persentase defect pada diagram pareto akan menjadi CTQ (kritis dan mayor). Perhitungan nilai sigma menggunakan tahapan rumus Defect Per Unit (DPU), Defect Per Oppurtunities (DPO), dan Defect Per Million Oppurtunities (DPMO).
Adapun tahapan rumus adalah sebagai berikut (Sari \& Bernik, 2018) :

$$
\begin{aligned}
& \text { DPU }=\frac{\text { Total kerusakan }}{\text { Total Produksi }} \\
& \text { DPO }=\frac{\text { Total kerusakan }}{\text { Total Produksi x peluang kerusakan }}
\end{aligned}
$$

$$
\mathrm{DPMO}=\mathrm{DPO} \times 1.000 .000
$$

Konversi nilai DPMO ke nilai sigma dilakukan menggunakan rumus excel dengan rumus sebagai berikut (Kusumawati, \& Fitriyeni, 2017)

Konversi nilai DPMO $=$ NORMSINV ((1.000.000-DPMO)/1.000.000)+1.5.

3. Analyze : Pada tahap ini dilakukan pencarian penyebab dari defect menggunakan diagram sebab akibat. Penggunaan diagram sebab akibat yang pada tahap analyze dilakukan untuk menemukan dan menentukan penyebab cacat (Kurniawan, 2019).

4. Improve : Pada tahap ini dilakukan kesimpulan mengenai hasil dari diagram sebab akibat berdasarkan unsur penyebab, defect, faktor penyebab, dan usulan perbaikan menggunakan prinsip $5 \mathrm{~W}+1 \mathrm{H}$ (Tannady \& Chandra, 2016).

5. Control : Pada tahap ini diharapkan usulan perbaikan yang dilakukan oleh penulis mendapat pengawasan dan perhatian pada bagian produksi. Tindakan berupa usulan perbaikan dilakukan penekanan untuk pendokumentasian dan penyebarluasan pada tahap control.

\section{Hasil dan Pembahasan}

\section{Tahap Define}

Tahap pertama pada proses six sigma adalah define. Pada tahap define dilakukan pencarian terhadap permasalahan yang terdapat pada alur bisnis PT X. Pada penelitian kali ini, identifikasi permasalahan dilakukan berdasarkan ketersediaan data produksi di mana proses dilakukan pada mesin ISBM dengan output botol personal care merek $\mathrm{X}$ untuk jenis $250 \mathrm{ml}$ dan 500 $\mathrm{ml}$. Penggunaan diagram SIPOC pada tahap define dilakukan untuk mengidentifikasi permasalahan dan perumusan tujuan yang hendak dicapai (Rimantho, \& Mariani, 2017). Diagram SIPOC ditunjukan pada Tabel 2. Berdasarkan hasil Diagram SIPOC botol personal care, terdapat masalah pada tahap proses dengan permasalahan berupa reject yang dihasilkan pada saat proses running produksi. Pengumpulan data reject dilakukan sebagai identifikasi jenis defect yang dihasilkan pada botol personal care. Produk personal care memiliki jenis defect yaitu critical dan major. 
Data yang didapat merupakan data produksi periode Januari 2019 - Januari 2020 dengan persentase reject yang akan ditampilkan pada Tabel 3. Data yang didapatkan tidak menggunakan uji kecukupan data. Penelitian yang dilakukan dengan hasil analisa yang sudah dilakukan perusahaan, tidak perlu dilakukan uji kecukupan data karena data tersebut tidak mencakup hasil observasi atau kuisioner dengan teknik berupa sampel acak (Rosihin et al., 2017). Berdasarkan hasil perhitungan persentase reject, botol personal care $250 \mathrm{ml}$ memiliki persentase

Tabel 2. Diagram SIPOC Botol Personal Care

\begin{tabular}{|c|c|c|c|c|}
\hline Supplier & Input & Process & Output & Customer \\
\hline Supplier PET & Raw Material (Resin PET) & Material & Raw Material (Pass) & PPIC (Warehouse) \\
\hline PPIC (Warehouse) & Raw Material Planning & Material Transfer & Raw Material & ISBM Prod Dept \\
\hline ISBM Prod Dept & Raw Material & Drying & Raw Material & ISBM Prod Dept \\
\hline ISBM Prod Dept & Raw Material & Barrel and Screw & Melted Material & ISBM Prod Dept \\
\hline ISBM Prod Dept & Melted Material & Injection & Melted Material & ISBM Prod Dept \\
\hline ISBM Prod Dept & Melted Material & Preform Forming & Preform & ISBM Prod Dept \\
\hline ISBM Prod Dept & Preform & Conditioning & Preform & ISBM Prod Dept \\
\hline ISBM Prod Dept & Preform & Stretch and Blow & Blank Bottle PET Personal Care & ISBM Prod Dept \\
\hline ISBM Prod Dept & $\begin{array}{l}\text { Blank Bottle PET Personal } \\
\text { Care }\end{array}$ & Ejected Bottle & Packed Bottle (Gray Area) & ISBM Prod Dept \\
\hline ISBM Prod Dept & Packed Bottle (Gray Area) & Transfer & $\begin{array}{c}\text { Labeled Code, Documents, and } \\
\text { Packed Bottle }\end{array}$ & PPIC (Warehouse) \\
\hline PPIC (Warehouse) & $\begin{array}{l}\text { Labeled Code, Documents, } \\
\text { and Packed Bottle }\end{array}$ & Delivery & $\begin{array}{c}\text { Blank Bottle PET Personal Care } \\
\text { (Packed bottle) }\end{array}$ & Brand Owner \\
\hline
\end{tabular}

Tabel 3. Persentase Reject Botol Personal Care $250 \mathrm{ml}$ dan $500 \mathrm{ml}$

\begin{tabular}{|l|l|l|l|l|l|l|}
\hline \multirow{2}{*}{ Bulan } & \multicolumn{3}{|c|}{ PET 250ml } & \multicolumn{3}{c|}{ PET 500ml } \\
\cline { 2 - 7 } & $\begin{array}{l}\text { Jumlah } \\
\text { Produksi }\end{array}$ & $\begin{array}{l}\text { Reject } \\
\text { Produksi }\end{array}$ & Persentase & $\begin{array}{l}\text { Jumlah } \\
\text { Produksi }\end{array}$ & $\begin{array}{l}\text { Reject } \\
\text { Produksi }\end{array}$ & Persentase \\
\hline Januari 2019 & 958.562 & 8.050 & 0,8398 & 199.368 & 4.752 & 2,3835 \\
\hline Februari 2019 & 594.099 & 4.857 & 0,8175 & 146.988 & 2.882 & 1,9607 \\
\hline Maret 2019 & 586.619 & 6.613 & 1,1273 & 178.200 & 3.742 & 2,0999 \\
\hline April 2019 & 1.230 .273 & 12.979 & 1,0549 & 198.720 & 4.060 & 2,0430 \\
\hline Mei 2019 & 589.424 & 5.318 & 0,9022 & 90.720 & 1.685 & 1,8573 \\
\hline Juni 2019 & 361.845 & 4.009 & 1,1079 & 90.720 & 1.785 & 1,9676 \\
\hline Juli 2019 & 108.086 & 1.018 & 0,9418 & 91.478 & 2.102 & 2,2978 \\
\hline Agustus 2019 & 273.955 & 1.997 & 0,7289 & - & - & - \\
\hline September 2019 & 600.254 & 4.870 & 0,8113 & 65.124 & 1.601 & 2,4584 \\
\hline Oktober 2019 & 257.499 & 2.541 & 0,9868 & - & - & - \\
\hline November 2019 & 964.546 & 7.778 & 0,8064 & 116.748 & 2.917 & 2,4985 \\
\hline Desember 2019 & 737.902 & 6.194 & 0,8394 & 267.840 & 6.100 & 2,2775 \\
\hline Januari 2020 & 765.785 & 6.883 & 0,8988 & 251.856 & 5.869 & 2,3303 \\
\hline Total & 8.028 .849 & 73.107 & 0,9105 & 1.697 .762 & 37.495 & 2,2085 \\
\hline
\end{tabular}

\section{Tahap Measure}

Pada tahap measure, dilakukan identifikasi defect terlebih dahulu sebagai CTQ. Identifikasi CTQ yang sudah ditetapkan selanjutnya dilakukan penghitungan nilai sigma. Identifikasi CTQ menggunakan dua pendekatan. Pendekatan pertama dilakukan dengan mengidentifikasi cacat dominan yang ditetapkan menjadi CTQ pada diagram pareto, sedangkan pendekatan kedua di mana merupakan penetapan keseluruhan karakteristik defect untuk penggunaan six sigma menjadi CTQ sesuai dengan kebutuhan dan ekspektasi pelanggan. reject produksi sebesar 0.9105. Pada botol personal care $500 \mathrm{ml}$ memliki rata-rata persentase reject produksi sebesar $2.2085 \%$. Persentase reject yang dihasilkan pada botol volume $500 \mathrm{ml}$ melebihi standar reject perusahaan sebesar $2 \%$. Oleh karena itu, penelitian ini akan berfokus pada botol bervolume $500 \quad \mathrm{ml}$. 


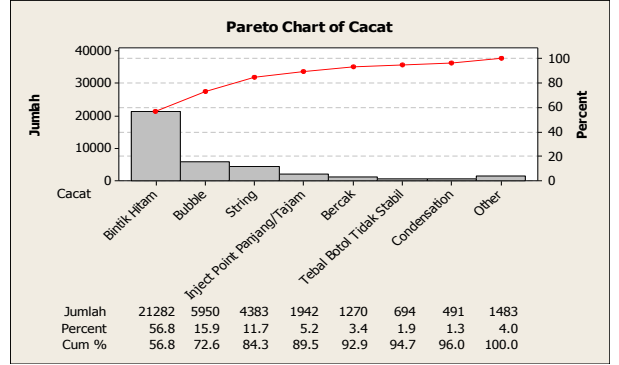

Gambar 2. Diagram Pareto

Perhitungan nilai sigma yang dilakukan berdasarkan Sari dan Bernik (2018) adalah sebagai berikut :

a. DPU $=\frac{\text { Total } \text { Reject Produksi }}{\text { Total Produksi }}=\frac{37.495}{1.697 .762}=0,022084957$

b. $\mathrm{DPO}=\frac{\text { Total Reject Produksi }}{\text { Total Produksi x peluang kerusakan }}$

$$
=\frac{37.495}{1.697 .762 \times 12}==0,001840413
$$

c. $\mathrm{DPMO}=\mathrm{DPO} \times 1.000 .000=1840,413$

d. Konversi DPMO ke nilai sigma $=4,40429377$

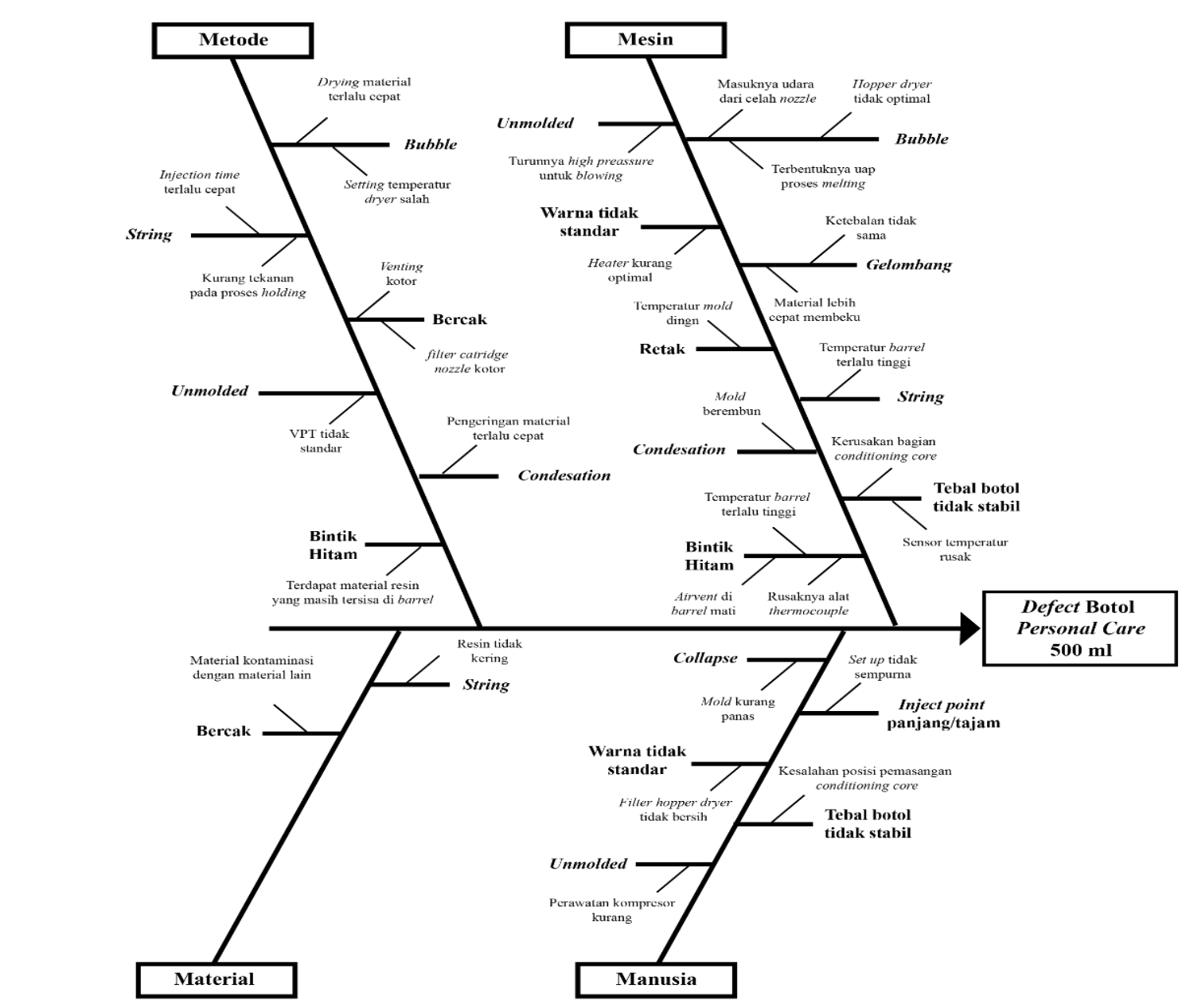

Gambar 4. Diagram Sebab Akibat

\section{Tahap Analyze}

Pada tahap ini, hasil analisis dibuat berdasarkan penyebab defect pada produk. Defect pada produk tidak menjamin secara keseluruhan hilang walaupun menggunakan bahan recycle dengan teknologi injection molding. Perlu adanya tindakan perbaikan terhadap masalah defect running produksi pada mesin ISBM di PT X. Masalah yang dihadapi oleh suatu perusahaan dilakukan dengan pengumpulan beberapa orang ahli pada permasalahan (Sari \& Mulyanto, 2019). Pada botol personal care $500 \mathrm{ml}$, fokus permasalahan terdapat pada 12 defect yang harus dilakukan perbaikan dengan informasi penyebab berasal dari pendokumentasian yang sudah dilakukan oleh PT X yang ahli pada permasalahan. 12 defect mempunyai 4 faktor penyebab yaitu mesin, manusia, material dan metode. Dari faktor-faktor tersebut digunakan diagram sebab akibat (fish bone) sebagai analisis dari masalah yang disajikan pada Gambar 4 . 
Tabel 7. Pemberian Saran Usulan 5W $+1 \mathrm{H}$ pada Defect Botol Personal Care

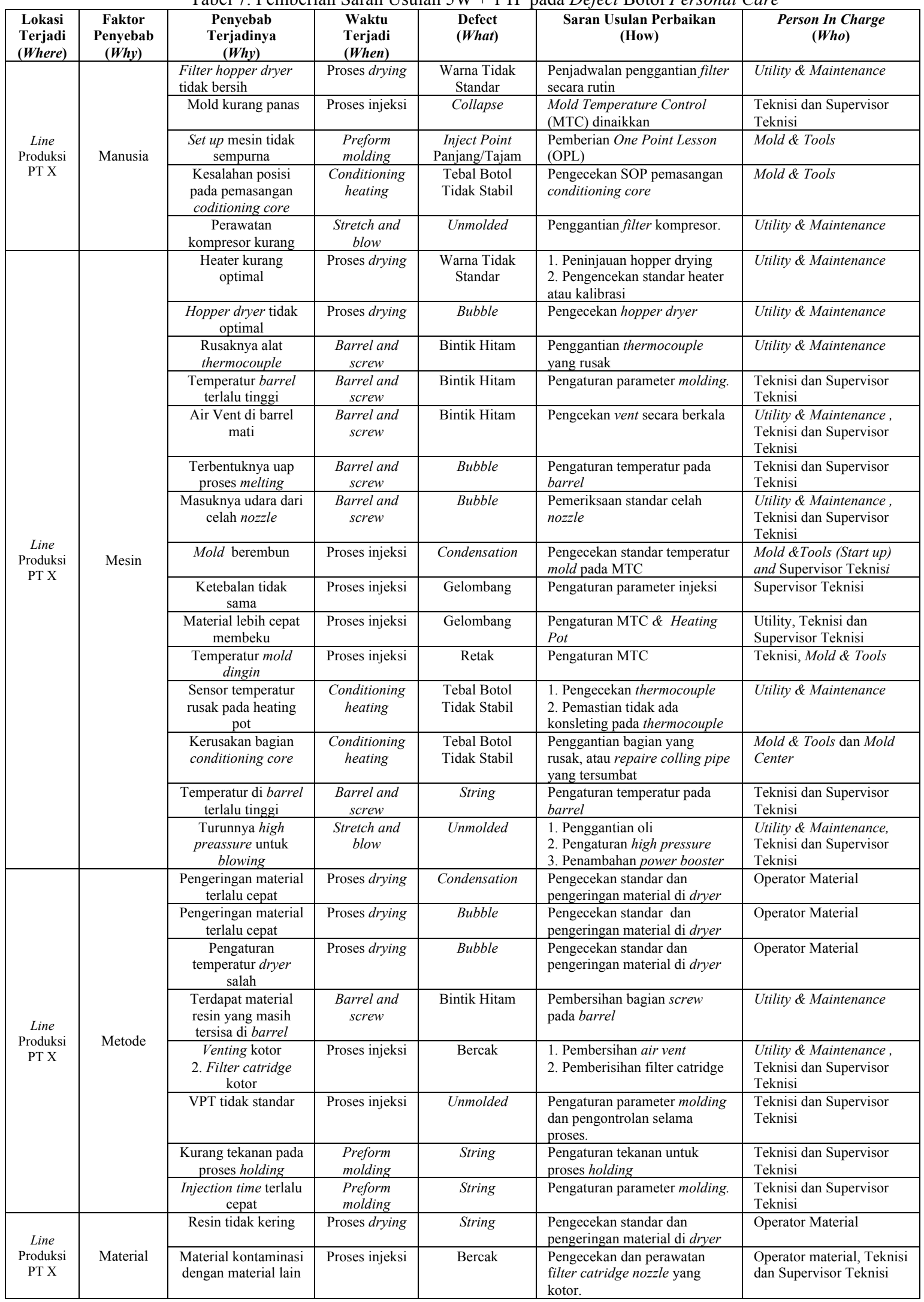




\section{Tahap Improve}

Prinsip $5 \mathrm{~W}+1 \mathrm{H}$ ( What, When, Who, Where, Why, How) dilakukan pada tahapan improve sebagai pemberian usulan perbaikan. (Tannady \& Chandra, 2016). Penggunaan $5 \mathrm{~W}+1 \mathrm{H}$ dilakukan pada faktor man, machine, method dan material secara terpisah (Bakti \& Lauhmahfudz, 2018). Where pada $5 \mathrm{~W}+1 \mathrm{H}$ menunjukkan lokasi perusahaan tempat penelitian dilakukan (Lestari \& Junaidy, 2019). How pada $5 \mathrm{~W}+1 \mathrm{H}$ merupakan bagaimana cara memperbaiki (Trenggonowati, \& Arafiany, 2018). Tabel 7 merupakan hasil dari pemberian usulan yang disarankan sebagai continous improvement untuk pengurangan jumlah reject pada botol personal care berdasarkan wawancara mendalam pada pihak terkait.

\section{Tahap Control}

Penelitian ini tidak melakukan implementasi dalam melihat perubahan nilai six sigma sebelum pemberian usulan dan sesudah pemberian usulan pada tahap control,. Usulan yang sudah diberikan diharapkan dapat diimplementasikan pada botol jenis personal care dan dapat menaikkan nilai sigma dalam hal pengendalian kualitas. Tahapan control menegaskan untuk pendokumentasian dan penyebarluasan tindakan (Didiharyono, et al, 2018). Dalam hal pengendalian kualitas, perusahaan perlu menerapkan sistem continuous improvement di mana peningkatan harus dilakukan secara terus-menerus dan tidak berhenti pada suatu pencapaian. Standardisasi yang harus dicapai pada suatu produk diharapkan dapat menjaga kestabilan output produk agar tidak melewati batas toleransi yang telah ditetapkan. Jika ditemukan adanya defect yang melewati standar maka perusahaan harus melakukan pengendalian produksi dari faktor mesin, manusia, metode, dan material. Dalam hal ini, perlu adanya alat bantu statistik dalam proses pengendalian kualitas serta dokumentasi agar penyebab defect yang terjadi tidak terulang kembali. Selain itu, pengawasan terhadap pencatatan defect yang dihasilkan harus lebih diperhatikan agar perbaikan dapat dilakukan secepatnya.

\section{Kesimpulan}

Berdasarkan hasil dari penelitian yang telah dilakukan dan permasalahan yang terjadi, dapat disimpulkan bahwa penelitian ini telah memberikan usulan perbaikan mengenai permasalahan defect botol personal care $500 \mathrm{ml}$.
Berdasarkan rata rata persentase defect reject personal care $500 \mathrm{ml}$ dengan hasil 2,363\% maka penelitian ini berfokus pada permasalahan objek tersebut. Botol personal care $500 \mathrm{ml}$ memiliki 12 jenis defect yang menjadi CTQ yaitu bintik hitam, bercak, bubble, collapse, condensation, gelombang, inject point panjang/tajam, retak, string, tebal botol tidak stabil, unmolded, warna tidak standar. Hasil perhitungan nilai sigma dalam pengendalian kualitas botol personal care yaitu 4,40429377 dengan DPMO sebesar 1840,413. Pemberian usulan perbaikan dilakukan dengan melihat 4 faktor permasalahan pada manusia, mesin, material, dan metode. Pendokumentasian atas permasalahan dapat meminimalisasi beban permasalahan pada defect yang sama.

Saran yang dapat diberikan untuk penelitian selanjutnya adalah melakukan implementasi terhadap permasalahan dalam pengendalian kualitas hingga mendapatkan perbedaan nilai sigma sesudah menerapkan usulan perbaikan. Data dilengkapi dengan data sampling agar bisa meminimalisasi kesalahan penghitungan data pada bagian produksi. Penelitian akan lebih baik dilakukan untuk pengambilan data dalam waktu jauh hari agar bisa menghitung nilai perbedaan sigma. Meminimalisasi permintaan data berupa keuangan karena sangat sensitif.

\section{Daftar Pustaka}

Salomon, L. L., Ahmad, \& Limanjaya, N. D. (2015). Strategi Peningkatan Mutu Part Bening Menggunakan Pendekatan Metode Six Sigma (Studi Kasus: Departemen Injection Di PT.KG). Jurnal Ilmiah Teknik Industri, 3(3), 156-165.

Didiharyono, Marsal, \& Bakhtiar. (2018). Analisis Pengendalian Kualitas Produksi Dengan Metode Six Sigma Pada Industri Air Minum PT Asera Tirta Posidonia, Kota Palopo. Jurnal Sainsmat, 3(2), 163-176.

Indrawansyah, I., \& Cahyana, B. J. (2019). Analisa Kualitas Proses Produksi Cacat Uji Bocor Wafer Dengan Menggunakan Metode Six Sigma Serta Kaizen Sebagai Upaya Mengurangi Produk Cacat di PT XYZ. Seminar Nasional Sains dan Teknologi, (pp. 1-8). Jakarta.

Kurniawan, W., Sugiarto, D., \& Saputera , R. (2017). Usulan Penerapan Metode Six Sigma Untuk Meningkatkan Mutu Crude Palm Oil (CPO) di PT. X. Jurnal Ilmiah Teknik Industri, 5(2), 85-91. 
Ahmad, F. (2019). Six Sigma DMAIC sebagai Metode Pengendalian Kualitas Produk Kursi Pada UKM. Jurnal Integerasi Sistem Industri, 6(1), 1117.

Gaspersz, V. (2005). Total Quality Management. Jakarta: PT Gramedia Pustaka Utama.

Kaban, R. (2014). Pengendalian Kualitas Kemasan Plastik Pouch Menggunakan Statistical Procces Control (Spc) Di Pt Incasi Raya Padang. Optimasi Sistem Industri, 13(1), 518-547.

Sari, I. A., \& Bernik, M. (2018). Penggunaan New And Old Seven Tools Dalam Penerapan Six Sigma Pada Pengendalian Kualitas Produk Stay Headrest. Jurnal Ekonomi Manajemen dan Bisnis, 19(1), 9-21.

Kusumawati, A., \& Fitriyeni, L. (2017). Pengendalian Kualitas Proses Pengemasan Gula Dengan Pendekatan Six Sigma. Jurnal Sistem dan Manajemen Industri, 1(1), 43-48.

Kurniawan, D. (2019). Penurunan Produk Cacat Dengan Metode Six Sigma Dan Continous Improvement Di PT.Cakra Guna Cipta. Jurnal Teknologi dan Manajemen Industri, 5(1), 8-14.

Tannady, H., \& Chandra, C. (2016). Analisis Pengendalian Kualitas Dan Usulan Perbaikan Pada Proses Edging Di PT Rackindo Setara Perkasa Dengan Metode Six Sigma. Journal of Industrial Engineering \& Management Systems, 123-139.
Rimantho, D., \& Mariani, D. M. (2017). Penerapan Metode Six Sigma Pada Pengendalian Kualitas Air Baku Pada Produksi Makanan. Jurnal Ilmiah Teknik Industri, 16(1), 1-12.

Rosihin, Ulinnuha, L. M., \& Cahyadi, D. (2017). Analisis Pengendalian Kualitas Super Absorbent Polymer Dengan Menggunakan Metode Six SIgma. Jurnal Sistem dan Manajemen Industri, 1(1), 19-28.

Sari, I. P., \& Mulyanto, A. (2019). Penerapan Total Quality Management Pada Perencanaan Kaizen Kualitas Plating di PT Surteckariya Indonesia Dengan Metode Fishbone Berbasis Android. Jurnal Informatika SIMANTIK, 4(2), 19.

Bakti, C. S., \& Lauhmahfudz, M. E. (2018). Penerapan Metode Six Sigma Dan Perbaikan Kerja Pada Pengendalian Kulaitas Sepatu CV.CIR. Jurnal STT YUPPENTEK, 9(1), 49-57.

Lestari, S., \& Junaidy, M. H. (2019). Pengendalian Kualitas Produk Compound AT807 Di Plant Mixing Center Dengan Metode Six Sigma Pada Perusahaan Ban Di Jawa Barat. Journal Industrial Servicess, 5(1), 100-106.

Trenggonowati, D. L., \& Arafiany, N. M. (2018). Pengendalian Kualitas Produk Baja Tulangan Sirip 25 Dengan Menggunakan Metode Spc Di Pt. Krakatau Wajatama Tbk. Journal Industrial Servicess, $\quad 3(2), \quad$ 122-131. 